\title{
Simulation and Optimization Scheme of Hull Segment Manufacturing Planning Management
}

\section{Li Jun}

\begin{abstract}
Based on the modern system of shipbuilding planning management, taking the equipment of the hull workshop of a shipyard as the unit modeling, by combining the design of BOM, production plan, production process, production process and logistics with the Plant simulation, the genetic algorithm and process reengineering technology from the platform are used to optimize the production bottleneck and improve the utilization rate of equipment so that the plan can be balanced and continuous production.
\end{abstract}

Index Terms - Simulation; Hull Manufacturing ;process Reengineering Technology; Planning Management

\section{INTRODUCTION}

The so-called modern shipbuilding mode is under the guidance of the overall optimization theory, applying the principle of group technology, taking the intermediate products as the guide, organizing the production according to the region. The shell outfitting and painting operation are separated in space and orderly in time, realizing the integration of design, production and management, balanced and continuous assembly of shipbuilding[1]. With the popularization and development of modern computer and the proposal of national industry 4.0, it leads the development of industrial digital intelligence. Shipbuilding is a multi-type and multi-resource, complex and comprehensive production process, but the planning management system is the core of the effective operation of enterprises. The idea of lean shipbuilding is widely used in shipyards, which brings new management ideas to shipbuilding enterprises. In the process of design and manufacture of ship products in modern shipyards, the application of virtual simulation technology has played a great role, which provides an implementation means for the accurate control and scheduling of production planning [2].

In this paper, taking the hull segmentation of a shipyard as the object, the hull construction system simulation model of a shipyard is constructed to simulate theexecution of the plan ned tasks in the process of construction. the bottleneck is fou nd out and the optimization scheme is put forward, by the col lection and analysis of the relevant data of workshop equipme nt, such asstation, quantity, waiting time and utilization rate of equipment, combined with the theory of production beat $\mathrm{e}$ quilibrium.

\section{Hull Section CONSTRUCTION PROCESS AND PLANNING MANAGEMENT}

Ship segmented construction system is a complex discrete event system, and the simulation of this kind of system is generally realized by event scheduling method[3].The hull

Jun Li, School of Naval Architecture \& Ocean Engineering, Jiangsu University of Science and Technology, Zhenjiang, Jiangsu, China. section construction is the result of the separation of time and space in the modern shipbuilding mode, and the hull manufacturing process is carried out according to the hierarchy and based on the intermediate products. The hull manufacturing process mainly includes: pretreatment, cutting, small stand and large group stand, in which the pretreatment carries on the correction, rust removal and primer work to the steel before the material.Marine steel often has all kinds of deformation due to uneven rolling, uneven cooling shrinkage after rolling or other factors in the process of transportation and storage.For this reason, after the plate and profile are removed from the steel yard, the plate and profile are corrected by multi-roll steel plate leveler and section steel straightener respectively in order to ensure the normal processing of material, edge and forming.The main tasks of cutting and cutting are the size, cutting and matching of the profile, the cutting of the internal components, the cutting of the outer plate of the hull surface, the bending and forming of the profile, as well as the cutting and welding of T profile, as well as groove opening and grinding. The main task of the team is to assemble the hull in a production stage, namely, to make up the production process of two or more parts,such as assembling $\mathrm{T}$ profiles, ribs on the installation of reinforcement, reinforcement holes and so on. Large group assembly, also known as hull segmented assembly, is mainly a production management mode of ship manufacturing, which is a production stage of hull segmented assembly, namely, the production process of segmented parts and components.

The ship section construction generally adopts the inverted arrangement plan, formulates the company's lineschedule $\mathrm{pl}$ an according to the delivery date at first, then determines the construction policy according to thesection or general segme nt division plan, and determines the ship large node plan.On the basis of the loading network diagram, The ship section co nstruction reverses the middle schedule of each segment, and makesthe monthly plan and weekly plan according to the pro cessing capacity of the workshop equipment.Hull constructio $\mathrm{n}$ planning management is mainly the preparation of worksho $\mathrm{p}$ production plan based on the advance schedule.

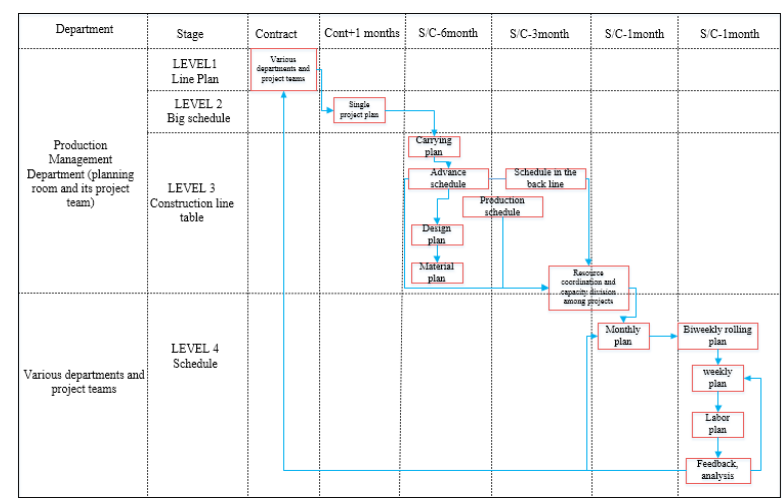

Figure 2 ship Planning Management System 


\section{SimUlation SCHEME OF HULl SEGMENT CONSTRUCTION}

Generally speaking, the basic step of system simulation is to establish a model on the computer for the real system at first, and then run and experiment on the simulation model to study the performance of the system[4].Ship construction system is a huge and complex system, which includes production workshop, production line, production equipment, warehouse, crane, forklift, staff, all kinds of equipment and management information. In the face of such a high complexity of the system,firstly,we need to abstract the essential characteristics of the simulation system, simplify the complexity of the model, start with the simpler model, select the appropriate modeling mode to build the system[5].Virtual simulation technology can be divided into continuous system simulation and discrete system simulation. Ship construction is a huge integrated manufacturing process, which belongs to discrete simulation.At present, there are a lot of software for discrete system simulation. The simulation platform selected in this paper is Siemens plant simulation,an object-oriented discrete event dynamic system simulation software, which is one of the best software for plant, production line and logistics process simulation and optimization. It has four basic modeling modules (1) logistics object, which refers to the object with the ability to change the parameters of moving object, such as machining machine tool, stacking area and so on. (2) Information flow object is the object of system control, transmission and collection of information, such as production line balance, bottleneck analysis, equipment utilization and so on. (3) the user interface object is a means for the user of the simulation model to communicate with the simulation model. It can not only provide the user with the relevant information of the system simulation, but also be used as a tool for the user to control the simulation. (4) moving object refers to the object whose physical position is not limited to one place but can be moved, such as parts, vehicles and pallets that are processed in the assembly line.

\section{A. Simulation target}

The main purposes of hull construction segment planning management simulation are to detect and evaluate the feasibility and continuity of the generation plan, to optimize the production allocation and resources of the workshop,to optimize the technological process of the workshop, and to determine the optimal optimization sequence of the production workshop to make the plan management more continuous and balanced production and so on.

\section{B. Research on the Scheme of Simulation system}

The simulation system can be divided into output, simulation platform, and simulation input. The input conditions and data are the objects of simulation modeling. The simulation model is established by the input data and process, material quantity and other information. The virtual simulation technology is used to dynamically simulate the real system of hull segmented manufacturing. The computer simulation platform is used to truly evaluate and generate the state of the manufacturing system without consuming any real resources. The simulation system evaluates the plan to ensure the feasibility of the plan and the accuracy of the material quantity and working hours, which is to accumulate data experience for the management of the assignment plan or the future series of ship plan.
At present, the simulation platform uses the plant simula tion software and its' method is process reengineering technol ogy. The output data is mainly the utilization rate of the equi pment, the production process and the system simulation sche me and so on.

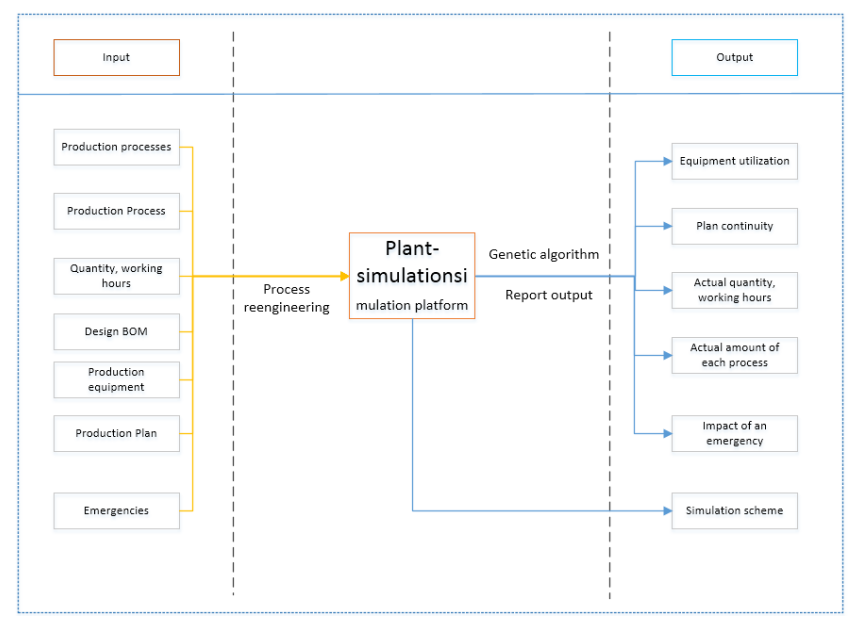

Figure 2 Simulation Scheme Research

\section{Flow Design of Simulation system}

The process can be basically simplified as follows: establishing the simulation object, determining the simulation parameters, formulating the simulation goal, running the simulation, analyzing the simulation results, optimizing the simulation model, analyzing the results before and after optimization, and outputting the optimization scheme of the system. Among them, there are many methods to optimize the scheme, such as genetic algorithm, experimental management method and ect as. The planning management is more controllable in the planned production control, the production rhythm is balanced and the flexible production of the workshop is very high by the simulation analysis of the workshop production bottleneck, optimize the workshop resources.

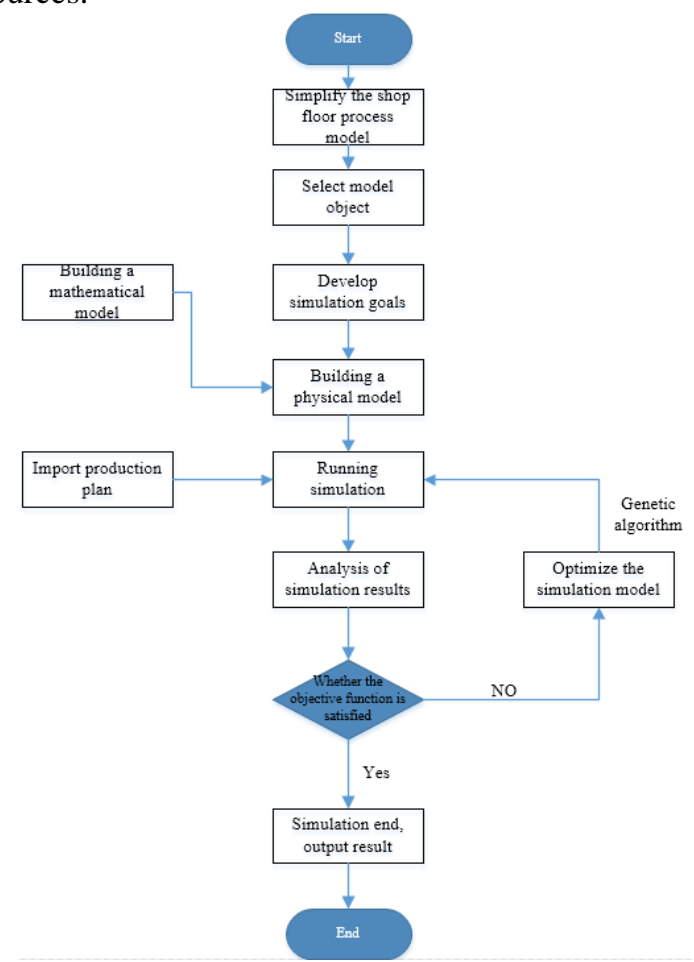

Figure 3 Optimization Scheme Of Simulation System 


\section{CONCLUSION}

By using the virtual simulation technology, the hull segment construction planning management is modeled by the process reengineering technology. And the actual generation status of the workshop is constructed by the object-oriented method in order to carry on the simulation evaluation to the ship segment construction plan management. Checking the rationality and feasibility of the plan is to reduce the blindness of the plan. By the study of the simulation scheme and combined with the actual production, the utilization rate of resources in the hull workshop can be improved in detail and the production efficiency can also be improved.

\section{REFERENCES}

[1] Wang Guiquan, Luo Xianhui, Han Bing. The planning of the manageme nt system of "intermediate product-oriented sub-channel manufacturin g". Management and Technology, 2003, 14 (2): 1.

[2] Wang Yue, Yao Wei, Jiang Zhiyong. Research on ship plane Segment p roduction Planning Adjustment Technology based on Virtual Simulati on [J]. China Shipbuilding, 2012(3): 192-198.

[3] Zhang Wei, Fan Liuqun, Ma Yumin. Digital Factory Technology and Ap plication [M]. Beijing: Mechanical Industry Press, 2006: 93-99.

[4] Wang Zhengzhong. Complex system simulation method and its applicat ion [J]. Computer Simulation, 2001 (1): 3-5.

[5]Luo Dai, Liu Cungen, Zhang Dian. Simulation of ship Construction syst em based on Workshop Unit [J]. China Shipbuilding, 2011, 52 (3): 20 $4-213$.

Jun Li, School of Naval Architecture \& Ocean Engineering, Jiangsu University of Science and Technology, Zhenjiang, Jiangsu, China. 